ADVERTISING AND CONSUMPTION:

A THEORETICAL ANALYSIS

by

E. Antony Selvanathan

Department of Economics

University of Western Australia

Discussion Paper 87.06

June 1987

ISSN 0811-6067

ISBN $0-86422-722-1$ 
May 1987

ADVERTISING AND CONSUMPTION: A THEORETICAL ANALYSIS

by

E. Antony Selvanathan ${ }^{*}$

Economic Research Centre

Department of Economics

The University of Western Australia

* This paper is a part of my Ph.D. thesis submitted at Murdoch University. I would like to thank Professor Kenneth W. Clements for his helpful comments. 
1. Introduction $\quad \ldots \ldots \ldots \ldots \ldots \ldots \ldots \ldots \ldots \ldots \ldots \ldots \ldots \ldots \ldots \ldots$

2. Advertising and Consumption $\ldots \ldots \ldots \ldots \ldots \ldots \ldots \ldots \ldots \ldots \ldots \ldots \ldots$

A Brief Review of Previous Results $\ldots \ldots \ldots \ldots \ldots \ldots .2$

Extension for Advertising $\ldots \ldots \ldots \ldots \ldots \ldots \ldots \ldots \ldots, 4$

3. The Comparative Statics of Advertising $\ldots \ldots \ldots \ldots \ldots \ldots$

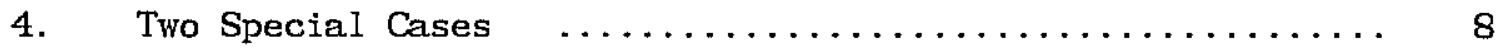

The First Special case $\ldots \ldots \ldots \ldots \ldots \ldots \ldots \ldots \ldots .6$

The Second Special case $\ldots \ldots \ldots \ldots \ldots \ldots \ldots \ldots . \ldots \ldots$

5. Indexes of Advertising $\quad \ldots \ldots \ldots \ldots \ldots \ldots \ldots \ldots \ldots \ldots \ldots \ldots$

6. A Differential Demand System With Advertising $\ldots \ldots \ldots \ldots . \quad 12$

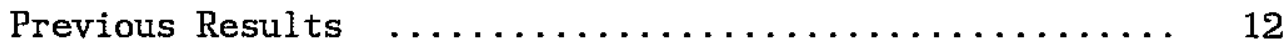

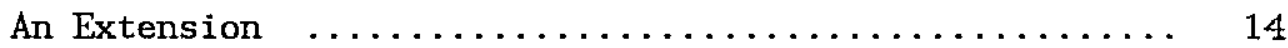

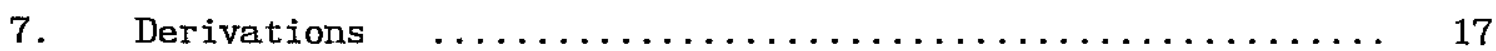

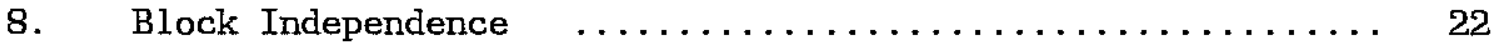

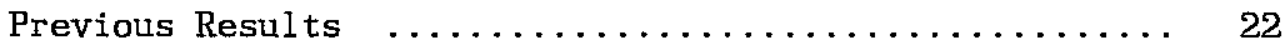

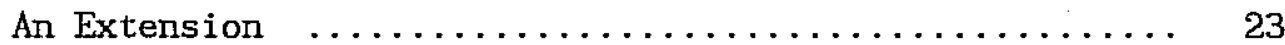

9. A Groupwise Index of Advertising $\ldots \ldots \ldots \ldots \ldots \ldots \ldots \ldots \ldots$

10. The Composite Demand Equations $\ldots \ldots \ldots \ldots \ldots \ldots \ldots \ldots .28$

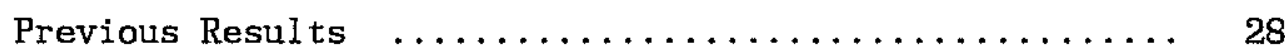

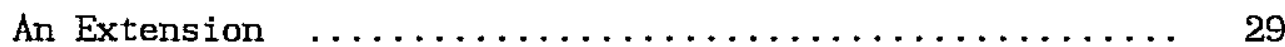


11. Conditional Demand Equations $\quad \ldots \ldots \ldots \ldots \ldots \ldots \ldots \ldots \ldots . . \ldots \ldots$

Previous Results $\ldots \ldots \ldots \ldots \ldots \ldots \ldots \ldots \ldots \ldots \ldots \ldots \ldots \ldots \ldots$

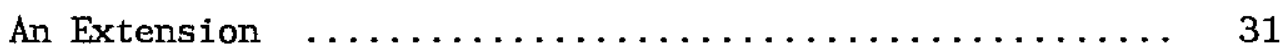

12. Conditional Demand Equations in Absolute Prices $\ldots \ldots \ldots \ldots .32$

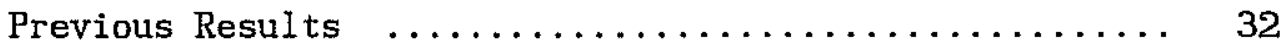

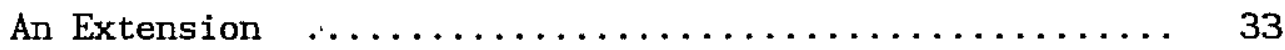

13. The Unconditional Demand Equations $\ldots \ldots \ldots \ldots \ldots \ldots \ldots \ldots$

14. More Derivations $\quad \ldots \ldots \ldots \ldots \ldots \ldots \ldots \ldots \ldots \ldots \ldots \ldots \ldots \ldots$

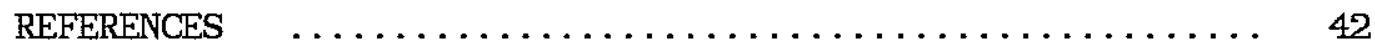




\title{
ADVERTISING AND CONSUMPTION: A THEORETICAL ANALYSIS
}

by

\author{
E. Antony Selvanathan \\ Economic Research Centre \\ Department of Economics \\ The University of Western Australia
}

\section{Introduction}

The traditional approach to consumption theory analyses the demand for a commodity in terms of the consumer's income and prices. This paper extends the differential approach to consumption theory (Theil, 1980) to analyse the effects of advertising. We give a comparative statics analysis of advertising and results on seperability of the consumer's utility function in the presence of advertising. This paper is exclusively theoretical. In a subsequent paper we apply this theoretical framework to U.K. alcohol data, Selvanathan (1987).

We commence this paper by extending the usual consumer demand problem to deal with advertising. We then develop a differential demand system with advertising variables. Under block independence, we obtain demand equations for groups of goods in which income, prices and advertising of the group play a role. Block independence also leads to demand equations for goods within each group. We show that under certain assumptions, the within group (or conditional) demand equations contain only total consumption of the group, prices and advertising of goods within the group. 


\section{Advertising and Consumption}

In this section initially we review the traditional consumer maximization problem and the solution to Barten's (1964) fundamental matrix equation. This material is a brief summary of the relevant parts in Theil (1980a). Then we extend the analysis for advertising.

\section{A Brief Review of Previous Results}

The consumer's utility function is

$$
\mathrm{u}=\mathrm{u}(\mathbf{q})
$$

where $\mathbf{q}=\left[\begin{array}{lll}q_{1} & \cdots & q_{n}\end{array}\right]^{\prime}$ is the quantity vector. To maximize $u(q)$ subject to the budget constraint, $\mathbf{p}^{\prime} \mathbf{q}=\mathrm{M}$, we form the Lagrangian function $u^{*}(\mathbf{q}, \lambda)=u(q)-\lambda\left(\mathbf{p}^{\prime} \mathbf{q}-\mathrm{M}\right)$, where $\lambda$ is the Lagrangian multiplier; $\mathbf{p}=\left[\mathrm{p}_{1} \ldots \mathrm{p}_{\mathrm{n}}\right]^{\prime}$ is the price vector; and $M$ is income. The first-order conditions are

$$
\frac{\partial u}{\partial \mathbf{q}}=\lambda \mathbf{p}
$$

and

$$
\mathbf{p}^{\prime} \mathbf{q}=\mathbf{M}
$$

The solution to the first-order conditions results in a system of demand 
equations of the form

$$
q=q(M, p) \quad \text { or } \quad q_{i}=q_{i}\left(M, p_{1}, \ldots, p_{n}\right), \quad i=1, \ldots, n
$$

By differentiating the first-order conditions (2.2) and (2.3) with respect to $\mathrm{p}$ and $\mathrm{M}$ we obtain

$$
\mathrm{U} \frac{\partial \mathbf{q}}{\partial \mathbf{p}^{\prime}}=\lambda I+\mathbf{p} \frac{\partial \lambda}{\partial \mathbf{p}^{\prime}}, \quad \quad \mathbf{p}^{\prime} \frac{\partial \mathbf{q}}{\partial \mathbf{p}^{\prime}}=-\mathbf{q}^{\prime},
$$

$$
\mathrm{U} \frac{\partial \mathbf{q}}{\partial M}=\frac{\partial \lambda}{\partial M} \mathbf{p}, \quad \mathbf{p}^{\prime} \frac{\partial \mathbf{q}}{\partial M}=1,
$$

where $U=\left[\partial^{2} w \partial q_{i} \partial q_{j}\right]$ is the Hessian matrix of the utility function, which is symmetric negative definite. Combining equations (2.5) and (2.6) yields Barten's (1964) fundamental matrix equation. The solution for the compensated-price derivatives of the demand equations is

$$
\frac{\partial \mathbf{q}^{*}}{\partial \mathbf{p}^{\prime}}=\lambda U^{-1}-\frac{\lambda}{\partial \lambda \partial M} \frac{\partial \mathbf{q}}{\partial M} \frac{\partial \mathbf{q}^{\prime}}{\partial M} \text {. }
$$

where $\partial \mathbf{q}^{*} / \partial \mathbf{p}^{\prime}=\partial \mathbf{q} / \partial \mathbf{p}^{\prime}+(\partial \mathbf{q} / \partial M) \mathbf{q}^{\prime}$. It is obvious from equation (2.7) and the symmetry of $\mathrm{U}^{-1}$ that the compensated-cross-price slopes are symmetric,

$$
\frac{\partial \mathbf{q}^{*}}{\partial \mathbf{p}^{\prime}}=\frac{\partial \mathrm{q}^{*}}{\partial \mathrm{p}}
$$

Premultiplying both sides of the first equation of (2.6) by $\mathrm{U}^{-1}$ and taking the transpose we get

$$
\frac{\partial \mathbf{q}^{\prime}}{\partial M^{\prime}}=\frac{\partial \lambda}{\partial M} \mathbf{p}^{\prime} \mathbf{U}^{-1}
$$


where we have used the symmetry of $\mathrm{U}^{-1}$. Premultiplying both sides of (2.7) by $\mathbf{p}^{\prime}$ and using the above result we obtain

$$
\mathbf{p}^{\prime} \frac{\partial \mathbf{q}^{*}}{\partial \mathbf{p}^{\prime}}=\lambda \mathbf{p}^{\prime} U^{-1}-\frac{\lambda}{\partial \lambda / \partial M} \mathbf{p}^{\prime} \frac{\partial \mathbf{q}}{\partial M} \frac{\partial q^{\prime}}{\partial M}=0
$$

where we have also used the second equation in (2.6).

\section{Extension for Advertising}

Let $a_{i}$ be the advertising of $\operatorname{good} i(i=1, \ldots, n)$ and $a=\left[a_{i}\right]$ be the corresponding vector. We assume that $a_{i}$ is outside the control of the consumer, like $p_{i}$ and M. Following Barten (1977), we now postulate that the consumer's preferences can be described by means of a utility function of the form

$$
u=u(q, a) .
$$

We write the Hessian matrix of the utility function as

$$
\frac{\partial^{2} u}{\partial \zeta \partial \zeta^{\top}}=\left[\begin{array}{cc}
U & V \\
V^{\prime} & F
\end{array}\right] \text {, }
$$

where $\zeta=\left[\begin{array}{ll}\mathbf{q}^{\prime} & \mathbf{a}^{\prime}\end{array}\right]^{\prime} ; \mathbf{U}=\partial^{2} \mathrm{u} / \partial \mathbf{q} \partial \mathbf{q}^{\prime} ; \mathbf{V}=\partial^{2} \mathrm{u} / \partial \mathbf{q} \partial \mathbf{a}^{\prime} ;$ and $\mathbf{F}=\partial^{2} \mathrm{w} / \partial \mathbf{a} \partial \mathbf{a}^{\prime}$. As before, we assume that this Hessian is symmetric negative definite, which is needed for a budget-constrained utility maximum.

The Lagrangian for the maximization problem is now $\mathrm{u}^{*}(\mathbf{q}, \lambda)=$ $u(q, a)-\lambda\left(p^{\prime} \mathbf{q}-M\right)$. The first-order conditions are equations (2.2) and (2.3) with u given by (2.10). This maximization problem will result in 
a system of demand equations of the form

$$
q=q(M, p, a) \quad \text { or } \quad q_{i}=q_{i}\left(M, p_{1}, \ldots, p_{n}, a_{1}, \ldots, a_{n}\right), \quad i=1, \ldots, n \text {. }
$$

This is an extended version of the demand system (2.4).

\section{The Comparative Statics of Advertising}

In this section we shall analyse the effects of advertising on consumption by deriving the partial derivative matrix $\partial \mathbf{q} / \partial \mathbf{a}^{\prime}=\left[\partial \mathrm{q}_{i} / \partial a_{j}\right]$ and some related measures.

Differentiating (2.2) and (2.3) with respect to a we obtain

$$
\mathrm{U} \frac{\partial \mathbf{q}}{\partial \mathbf{a}^{\prime}}+\mathbf{V}=\mathbf{p} \frac{\partial \lambda}{\partial \mathbf{a}^{\prime}}, \quad \mathbf{p}^{\prime} \frac{\partial \mathrm{q}}{\partial \mathbf{a}^{\prime}}=0
$$

where $\mathrm{V}$ is a component of the Hessian matrix of the utility function

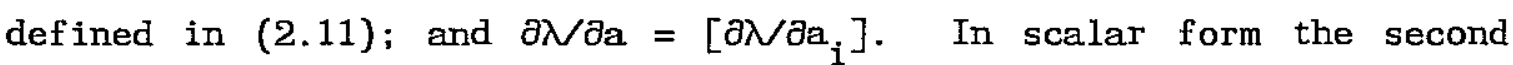
equation in (3.1) is $\sum_{i=1}^{n} p_{i}\left(\partial q_{i} / \partial a_{j}\right)=0$ for $j=1, \ldots, n$. This means that a change in the demand for one good due to advertising has to be compensated by a change in the demand for all other goods so that total expenditure remains constant. This property is analogous to (2.9).

Premultiplying both sides of (2.7) by $U$ and using the first equation of (2.6) we obtain

$$
U \frac{\partial \mathbf{q}^{*}}{\partial \mathbf{p}^{\prime}}=\lambda I-\frac{\lambda}{\partial \lambda \partial M} U \frac{\partial \mathbf{q}^{\prime}}{\partial M^{\prime}} \frac{\partial \mathbf{q}^{\prime}}{\partial M}=\lambda I-\lambda \mathbf{p} \frac{\partial \mathbf{q}^{\prime}}{\partial M}
$$

Taking the transpose of the above equation and postmultiplying both 
sides by $\partial q / \partial a^{\prime}$ gives

$$
\frac{\partial \mathbf{q}^{*}}{\partial \mathbf{p}^{\prime}} \mathrm{U} \frac{\partial \mathbf{q}}{\partial \mathbf{a}^{\prime}}=\lambda\left[\mathrm{I}-\frac{\partial \mathbf{q}}{\partial M^{\prime}} \mathbf{p}^{\prime}\right] \frac{\partial \mathbf{q}}{\partial \mathbf{a}^{\prime}}=\lambda \frac{\partial \mathbf{q}}{\partial \mathbf{a}^{\prime}}
$$

where we have used equation (2.8), the symmetry of $U$ and the second equation in (3.1). Premultiplying both sides of the first equation in (3.1) by $\partial q^{*} / \partial p^{\prime}$ we obtain

$$
\begin{aligned}
\frac{\partial \mathbf{q}^{*}}{\partial \mathbf{p}^{\prime}} \mathbf{U} \frac{\partial \mathbf{q}^{\prime}}{\partial \mathbf{a}^{\prime}} & =-\frac{\partial \mathbf{q}^{*}}{\partial \mathbf{p}^{\prime}} \mathbf{v}+\frac{\partial \mathbf{q}^{*}}{\partial \mathbf{p}^{\prime}} \mathbf{p} \frac{\partial \lambda}{\partial \mathbf{a}^{\prime}} \\
& =-\frac{\partial \mathbf{q}^{*}}{\partial \mathbf{p}^{\prime}} \mathbf{V},
\end{aligned}
$$

where the second step is based on (2.8) and (2.9). Combining this with equation (3.2) gives

$$
\frac{\partial \mathbf{q}}{\partial \mathbf{a}^{\prime}}=-\frac{1}{\lambda} \frac{\partial \mathbf{q}^{*}}{\partial \mathbf{p}^{\prime}} \mathbf{V}
$$

This shows that the effects of advertising on consumption are related to the substitution effects of price changes. This result is from Barten (1977).

We define $\mu_{i j}$ as the elasticity of the marginal utility of good $i$ with respect to advertising of good $j$,

$$
\frac{\partial\left[\log \frac{\partial u}{\partial q_{i}}\right]}{\partial\left(\log a_{j}\right)}=\mu_{i j}
$$


We can rewrite $(3.4)$ as

$$
\frac{\partial\left[\frac{\partial u}{\partial q_{i}}\right]}{\partial a_{j}}=\frac{\mu_{i j}\left[\frac{\partial u}{\partial q_{i}}\right]}{a_{j}}=\lambda \frac{p_{i} \mu_{i j}}{a_{j}},
$$

where for the second step we have used (2.2) in its scalar form. Noting that the left-hand side of the above equation is $\partial^{2} u / \partial q_{i} \partial a_{j}$, it can be written for $i, j=1, \ldots, n$ as

$$
V=\lambda P \mu A^{-1}
$$

where $\quad V=\partial^{2} w / \partial q \partial a^{\prime} ; \quad P=\operatorname{diag}\left[p_{1} \cdots p_{n}\right] ; \quad \mu=\left[\mu_{i j}\right] ; \quad$ and $\mathbf{A}=\operatorname{diag}\left[\mathrm{a}_{1} \ldots \mathrm{a}_{\mathrm{n}}\right]$. Premultiplying both sides of $(3.5)$ by $\partial \mathbf{q}^{*} / \partial \mathbf{p}^{\prime}$ gives

$$
\frac{\partial \mathbf{q}^{*}}{\partial \mathbf{p}^{\top}} \mathrm{V}=\lambda \frac{\partial \mathbf{q}^{*}}{\partial \mathbf{p}^{\prime}} \mathbf{P} \mathbf{p} \mathrm{A}^{-1}
$$

which when combined with (3.3) yields

$$
\frac{\partial \mathbf{q}}{\partial \mathbf{a}^{\prime}}=-\frac{\partial \mathbf{q}^{*}}{\partial \mathbf{p}^{\prime}} \mathbf{P} \boldsymbol{\mu} \mathbf{A}^{-1}
$$

Equation (3.6) can be expressed in elasticity form as

$$
\tau=\frac{\partial(\log q)}{\partial\left(\log a^{\prime}\right)}=-\eta^{*} \quad \text { or } \quad \tau_{i j}=\frac{\partial\left(\log q_{i}\right)}{\partial\left(\log a_{j}\right)}=-\sum_{k=1}^{n} \eta_{i k}^{*} \mu_{k j},
$$

where $T=\left[\tau_{i j}\right]=\left[\partial\left(\log q_{i}\right) / \partial\left(\log a_{j}\right)\right]$ is the matrix of advertising elasticities; and $\eta^{*}=\left[\eta_{i j}^{*}\right]$ is the matrix of compensated price 
elasticities. Equation (3.7) is a simple result showing again the link between the effects of advertising and the substitution effects.

\section{Two Special Cases}

In this section we analyse the implications of two special cases of the matrix $\left[\mu_{i j}\right]$.

\section{The First Special Case}

Consider the special case when the elasticity of the marginal utility of each good with respect to its own advertising is unity and when all the corresponding cross elasticities are zero. That is,

$$
\mu_{i j}= \begin{cases}1 & \text { if } i=j \\ 0 & \text { otherwise }\end{cases}
$$

so that $\boldsymbol{\mu}=\mathrm{I}$, the $\mathrm{n} \times \mathrm{n}$ identity matrix. In this situation (3.7) implies

$$
\tau_{i j}=-\eta_{i j}^{*}
$$

In words, the elasticity of consumption of $i$ with respect to advertising of $j$ is the negative of the corresponding (compensated) price elasticity. This means that $\tau_{i i}>0$ for $i=1, \ldots, n ; \tau_{i j}<0$ if $i$ and $j$ are net substitutes; and $\tau_{i j}>0$ if $i$ and $j$ are net complements. These results make sense since it is reasonable to expect that advertising will depress the sales of products which are substitutes for the good in question $\left(\eta_{i j}^{*}>0\right)$; and vice versa for complements. 


\section{The Second Special Case}

Next, consider the slightly more general case

$$
\mu_{i j}= \begin{cases}\mu & \text { if } i=j \\ 0 & \text { otherwise }\end{cases}
$$

where $\mu$ is a scalar, so that $\mu=\mu \mathrm{I}$. This kind of restriction has been considered by Theil (1980b). Here again all cross-advertising elasticities of the marginal utilities are zero, but now the own elasticities are non-unity. In this situation, the advertising elasticities of consumption are a constant multiple $-\mu$ of the corresponding price elasticities.

\section{Indexes of Advertising}

Consider the change in the marginal, utility of $j$ resulting from changes in the advertising of the $n$ goods. In logarithmic form this is

$$
\begin{aligned}
d\left[\log \frac{\partial u}{\partial q_{j}}\right] & =\sum_{k=1}^{n} \frac{\partial\left[\log \frac{\partial u}{\partial q_{j}}\right]}{\partial\left(\log a_{k}\right)} d\left(\log a_{k}\right) \\
& =\sum_{k=1}^{n} \mu_{j k} d\left(\log a_{k}\right)
\end{aligned}
$$

where the second step follows from definition (3.4). The right-hand side of the above equation can be considered as an index of advertising, where the "weights" are the elasticities $\mu_{j k}$. We shall write $d\left(\log \tilde{a}_{j}\right)$ 
for this index,

$$
d\left(\log \tilde{a}_{j}\right)=\sum_{k=1}^{n} \mu_{j k} d\left(\log a_{k}\right)
$$

We define a marginal-share-weighted average of
$d\left(\log \tilde{a}_{1}\right), \ldots, d\left(\log \tilde{a}_{n}\right)$ as

$$
d\left(\log \tilde{A}^{\prime}\right)=\sum_{j=1}^{n} \theta_{j} d\left(\log \tilde{a}_{j}\right)
$$

where $\theta_{j}=\partial\left(\mathrm{p}_{j} \mathrm{q}_{j}\right) / \partial \mathrm{M}$ is the marginal share of commodity $j$. This can be considered as an index of $d\left(\log \tilde{a}_{1}\right), \ldots d\left(\log \tilde{a}_{n}\right)$. Substituting for $d\left(\log \tilde{a}_{j}\right)$ from $(5.1)$ in (5.2) we can also express this index in terms of the $n$ original advertising variables, $d\left(\log a_{1}\right), \ldots d\left(\log a_{n}\right)$.

$$
\begin{aligned}
\mathrm{d}\left(\log \tilde{\mathrm{A}}^{\prime}\right) & =\sum_{j=1}^{\mathrm{n}} \theta_{j} \sum_{k=1}^{\mathrm{n}} \mu_{j k} \mathrm{~d}\left(\log a_{k}\right) \\
& =\sum_{k=1}^{n} h_{k} d\left(\log a_{k}\right),
\end{aligned}
$$

where

$$
h_{k}=\sum_{j=1}^{n} \theta_{j}{ }_{j k}
$$

Consider the situation when there is an equiproportionate change in advertising on each good, $d\left(\log a_{i}\right)=d(\log a)$ for $i=1, \ldots, n$. In 
this situation equation (5.1) becomes

$$
d\left(\log \tilde{a}_{j}\right)=\mu_{j} d(\log a)
$$

where $\mu_{\mathrm{j}}=\sum_{\mathrm{k}=1}^{\mathrm{n}} \mu_{\mathrm{jk}}$. This $\mu_{\mathrm{j}}$ is interpreted as the percentage increase in the marginal utility of $j$ resulting from a one percent increase in the advertising of each of the $\mathrm{n}$ goods. Using (5.4), (5.2) becomes

$$
d\left(\log \tilde{A}^{\prime}\right)=d(\log a) \sum_{j=1}^{n} \theta_{j^{\mu}}
$$

Let $\mu_{j}$ be the same for all $j$ and equal to a constant $\mu_{0}$, i.e.,

$$
\mu_{j}=\mu_{0}
$$

Then (5.4) and (5.5) imply that $d\left(\log \tilde{a}_{j}\right)=\mu_{0} d(\log$ a) and $d\left(\log \tilde{A}^{\prime}\right)=\mu_{o} d(\log a)$, respectively, where we have used $\sum_{j=1}^{n} \theta_{j}=1$. With restriction (5.6) an equiproportionate change in advertising of each good causes the relative advertising index, $d\left(\log \tilde{a}_{j} / A^{\prime}\right)$, to vanish:

$$
d\left[\log \frac{\tilde{a_{j}}}{\tilde{A^{\prime}}}\right]=d\left(\log \tilde{a}_{j}\right)-d\left(\log \tilde{A}^{\prime}\right)=0 .
$$

In what follows, to ensure that the relative advertising index vanishes for an equiproportionate change in advertising of all $\mathrm{n}$ goods, we shall impose constraint (5.6).

We return to the special case (4.1) whereby $\mu_{j k}=\delta_{j k}$, $\delta_{j k}$ being the Kronecker delta. Here $d\left(\log \tilde{a}_{j}\right)$ becomes $d\left(\log a_{j}\right)$ and consequently $d\left(\log \tilde{A}^{\prime}\right)$ becomes a marginal-share-weighted average of 
$d\left(\log a_{1}\right), \ldots, d\left(\log a_{n}\right)$, which we write as

$$
d\left(\log A^{\prime}\right)=\sum_{j=1}^{n} \theta_{j} d\left(\log a_{j}\right)
$$

This can be described as a Frisch index. In the second special case (4.2), $\mu_{j k}=\mu \delta \delta_{j k}, d\left(\log \tilde{a}_{j}\right)=\mu d\left(\log a_{j}\right)$ and the advertising index $\mathrm{d}\left(\log \tilde{\mathrm{A}}^{\prime}\right)$ is a multiple $\mu$ of the Frisch index. It is to be noted that these two special cases satisfy constraint (5.6), so that $d\left(\log \tilde{a}_{j} / \tilde{A}^{\prime}\right)$ vanishes for an equiproportionate change in advertising on all $\mathrm{n}$ goods.

\section{A Differential Demand System with Advertising}

In this section we shall briefly review the differential demand system associated with (2.4). This material is from Theil (1980a). We then derive a differential demand system with advertising.

\section{Previous Results}

The total differential of (2.4) is

$$
\mathrm{dq}_{i}=\frac{\partial \mathrm{q}_{i}}{\partial \mathrm{M}} \mathrm{dM}+\sum_{j=1}^{\mathrm{n}} \frac{\partial \mathrm{q}_{i}}{\partial \mathrm{p}_{j}} \mathrm{dp}_{j}, \quad \quad i=1, \ldots, \mathrm{n} .
$$

Transforming the above equation to logarithmic differential form by multiplying both sides by $p_{i} / M$ and using $w_{i}=p_{i} q_{i} / M$, we obtain

$$
\begin{aligned}
w_{i} d\left(\log q_{i}\right) & =\frac{\partial\left(p_{i} q_{i}\right)}{\partial M} d(\log M)+\sum_{j=1}^{n} \frac{p_{i} p_{j}}{M} \frac{\partial q_{i}}{\partial p_{j}} d\left(\log p_{j}\right) \\
& =\theta_{i} d(\log Q)+\sum_{j=1}^{n} v_{i j} d\left[\log \frac{p_{j}}{P^{\prime}}\right] .
\end{aligned}
$$


where $d(\log Q)=\sum_{i=1}^{n} w_{i} d\left(\log q_{i}\right)$ is the Divisia volume index; $v_{i j}$ is the $(i, j){ }^{\text {th }}$ price coefficient; and $d\left(\log P^{\prime}\right)=\sum_{j=1}^{n} \theta_{j} d\left(\log p_{j}\right)$ is the Frisch price index. The price coefficients are symmetric in $i$ and $j$ and satisfy

$$
\sum_{j=1}^{n} v_{i j}=\phi \theta_{i}
$$$$
i=1, \ldots, n \text {, }
$$

where $\phi$ is the income flexibility. Equation (6.1) is the $i^{\text {th }}$ differential demand equation in terms of relative prices.

To formulate demand equations in terms of the absolute prices we use the Slutsky coefficients defined as

$$
\pi_{i j}=\nu_{i j}-\phi \theta_{i} \theta_{j}
$$

The Slutsky coefficients are obviously also symmetric and, in view of (6.2), satisfy

$$
\sum_{j=1}^{n} \pi_{i j}=0
$$$$
i=1, \ldots, n,
$$

which is the homogeneity constraint. If we substitute for $v_{i j}$ from (6.3) the price term of (6.1) becomes

$$
\sum_{j=1}^{n} v_{i j} d\left[\log \frac{p_{j}}{P^{\prime}}\right]=\sum_{j=1}^{n} \pi_{i j} d\left(\log p_{j}\right)
$$


so that (6.1) takes the form

$$
w_{i} d\left(\log q_{i}\right)=\theta_{i} d(\log Q)+\sum_{j=1}^{n} \pi_{i j} d\left(\log p_{j}\right)
$$

This is the differential demand equation for good $i$ in terms of absolute prices.

\section{An Extension}

The total differential of (2.12) is

$$
\mathrm{dq}_{i}=\frac{\partial \mathrm{q}_{i}}{\partial \mathrm{M}} \mathrm{dM}+\sum_{j=1}^{n} \frac{\partial \mathrm{q}_{i}}{\partial \mathrm{p}_{j}} \mathrm{dp}_{j}+\sum_{j=1}^{n} \frac{\partial \mathrm{q}_{i}}{\partial \mathrm{a}_{j}} \mathrm{da}_{j}, \quad i=1, \ldots, n
$$

As before, we transform the above equation to logarithmic differential form by multiplying both sides by $\mathrm{p}_{i} / \mathrm{M}$ and using $\mathrm{w}_{i}=\mathrm{p}_{i} \mathrm{q}_{i} / \mathrm{M}$ to give

$$
\begin{aligned}
w_{i} d\left(\log q_{i}\right)=\frac{\partial\left(p_{i} q_{i}\right)}{\partial M} d(\log M) & +\sum_{j=1}^{n} \frac{p_{i} p_{j}}{M} \frac{\partial q_{i}}{\partial p_{j}} d\left(\log p_{j}\right) \\
& +\sum_{j=1}^{n} \frac{p_{i} a_{j}}{M} \frac{\partial q_{i}}{\partial a_{j}} d\left(\log a_{j}\right)
\end{aligned}
$$

From equation (6.1) we have that the first two right-hand side terms of (6.7) equal $\theta_{i} d(\log Q)+\sum_{j=1}^{n} v_{i j} d\left[\log \left(p_{j} / P^{\prime}\right)\right]$, where $d(\log Q)$ and $\mathrm{d}\left(\log \mathrm{P}^{\prime}\right)$ are as before.

In Section 7 we show that the advertising term in (6.7) can be simplified to

$$
\sum_{j=1}^{n} \frac{p_{i} a_{j}}{M} \frac{\partial q_{i}}{\partial a_{j}} d\left(\log a_{j}\right)=-\sum_{j=1}^{n} v_{i j} d\left[\log \frac{\tilde{a_{j}}}{\tilde{A^{\prime}}}\right]
$$


where $d\left[\log \tilde{a}_{j} / \tilde{A}^{\prime}\right]=d\left(\log \tilde{a}_{j}\right)-d\left(\log \tilde{A}^{\prime}\right)$ with $d\left(\log \tilde{a}_{j}\right)$ and $d\left(\log \tilde{A}^{\prime}\right)$ as defined in (5.1) and (5.2), respectively. In view of (6.8) equation (6.7) becomes

$$
w_{i} d\left(\log q_{i}\right)=\theta_{i} d(\log Q)+\sum_{j=1}^{n} v_{i j}\left[d\left[\log \frac{p_{j}}{P^{\prime}}\right]-d\left[\log \frac{a_{j}}{\tilde{A}^{\prime}}\right]\right]
$$

This is the relative price version of the extended differential demand equation for commodity $i$. Equation (6.9) shows that the demand for good $i$ depends on total consumption, the relative price and relative advertising of each good. Under restriction (5.6), when there is an equiproportionate change in the advertising of all goods the relative advertising term in (6.9) vanishes.

Below equation (5.6) we pointed out that when $\mu=\mathrm{I}$, $d\left(\log \tilde{a}_{j}\right)=d\left(\log a_{j}\right)$ and $d\left(\log \tilde{A}^{\prime}\right)=d\left(\log A^{\prime}\right)$. Consequently, in this case the $j^{\text {th }}$ relative advertising term in equation (6.9) simplifies to $d\left(\log a_{j} / A^{\prime}\right)$, so that the last term in that equation becomes

$$
\sum_{j=1}^{n} v_{i, j}\left[d\left[\log \frac{p_{j}}{P^{\prime}}\right]-d\left[\log \frac{a_{j}}{A^{\prime}}\right]\right]
$$

The $j^{\text {th }}$ term in this sum involves only the relative price and advertising of good $j$. This is not true in equation (6.9) as in general $d\left(\log \tilde{a}_{j}\right)$ involves the advertising of all goods; see equation $(5.1)$.

Below equation (5.7) we showed that when $\mu=\mu I$, $\mathrm{d}\left(\log \tilde{a}_{j}\right)=\mu d\left(\log a_{j}\right)$, and $d\left(\log \tilde{A}^{\prime}\right)=\mu d\left(\log A^{\prime}\right)$. Hence the relative advertising index $d\left(\log \tilde{a}_{j} / \tilde{A}^{\prime}\right)$ becomes a multiple $\mu$ of $d\left(\log a_{j} / A^{\prime}\right)$. 
Consequently, the last term in equation (6.9) simplifies to

$$
\sum_{j=1}^{n} v_{i j}\left[d\left[\log \frac{p_{j}}{P^{\prime}}\right]-\mu d\left[\log \frac{a_{j}}{A^{\prime}}\right]\right]
$$

Again the $j^{\text {th }}$ term in this sum involves only the $j^{\text {th }}$ relative price and advertising.

Equation (6.9) is formulated in terms of relative (or deflated) prices and advertising. To obtain the demand equation in absolute (or undef lated) terms we write (6.9) as

(6.10) $w_{i} d\left(\log q_{i}\right)=\theta_{i} d(\log Q)+\sum_{j=1}^{n} v_{i j} d\left[\log \frac{p_{j}}{P^{\prime}}\right]-\sum_{j=1}^{n} v_{i j} d\left[\log \frac{\tilde{a}_{j}}{\tilde{A}^{\prime}}\right]$.

In Section 7 we show that

$$
\sum_{j=1}^{n} v_{i j} d\left[\log \frac{\tilde{a_{j}}}{\tilde{A^{\prime}}}\right]=-w_{i} \underset{j=1}{n} \tau_{i j} d\left(\log a_{j}\right)
$$

where $w_{i}=p_{i} q_{i} / M$ is the $i^{\text {th }}$ budget share; and $\tau_{i j}$ is the advertising elasticity defined in equation (3.7). Using (6.5) and (6.11), (6.10) becomes

(6.12) $w_{i} d\left(\log q_{i}\right)=\theta_{i} d(\log Q)+\sum_{j=1}^{n} \pi_{i j} d\left(\log p_{j}\right)+\sum_{j=1}^{n} \lambda_{i j} d\left(\log a_{j}\right)$. where $\lambda_{i j}=w_{i}{ }^{T}{ }_{i j}$ is the $(i, j)^{\text {th }}$ advertising coefficient. The above equation is the extended differential demand equation for commodity i in terms of undef lated variables.

In Section 7 we show that under restriction (5.6) the 
advertising coefficients $\lambda_{i j}$ satisfy

$$
\sum_{j=1}^{n} \lambda_{i j}=0
$$

Equation (6.13) implies that a proportionate change in all the advertising variables does not affect the demand for any good, income and prices remaining unchanged. The slutsky coefficients $\pi_{i j}$ continue to satisfy $(6.4)$.

Below equation (4.1) we showed that $\mu_{i j}=\delta_{i j}$ implies that $\tau_{i j}=-\eta_{i j}^{*}$. Therefore, $\lambda_{i j}=-w_{i} \eta_{i j}^{*}=-\pi_{i j}$ in this case. In view of this result, the demand equation (6.12) becomes

$$
w_{i} d\left(\log q_{i}\right)=\theta_{i} d(\log Q)+\sum_{j=1}^{n} \pi_{i j}\left[d\left(\log p_{j}\right)-d\left(\log a_{j}\right)\right]
$$

Here advertising acts as the deflator of each good's price change.

Below equation (4.2) we showed that when $\mu_{i j}=\mu \delta_{i j}, \tau_{i j}=-\mu \eta_{i j}^{*}$. This implies that $\lambda_{i j}=-\mu w_{i} \eta_{i j}^{*}=-\mu \pi_{i j}$, so that (6.12) becomes

$$
w_{i} d\left(\log q_{i}\right)=\theta_{i} d(\log Q)+\sum_{j=1}^{n} \pi_{i j}\left[d\left(\log p_{j}\right)-\mu d\left(\log a_{j}\right)\right]
$$

\section{Derivations}

We first derive result (6.8). The advertising term in (6.7) can be considered as the $i^{\text {th }}$ element of the $n \times 1$ vector

$$
\left[\sum_{j=1}^{n} \frac{p_{i} a_{j}}{M} \frac{\partial q_{i}}{\partial a_{j}} d\left(\log a_{j}\right)\right]
$$


This vector can be expressed as

$$
\left[\sum_{j=1}^{n} \frac{P_{i} a_{j}}{M} \frac{\partial q_{i}}{\partial a_{j}} d\left(\log a_{j}\right)\right]=\frac{1}{M} P \frac{\partial q}{\partial a^{\prime}} \operatorname{Ad}(\log a) .
$$

where $P=\operatorname{diag}\left[p_{1} \ldots p_{n}\right] ; \quad \partial q / \partial a^{\prime}=\left[\partial q_{i} / \partial a_{j}\right] ; \quad A=\operatorname{diag}\left[a_{1} \ldots a_{n}\right] ;$ and $d(\log a)=\left[d\left(\log a_{i}\right)\right]$.

Premultiplying both sides of (3.6) by (1/M)P and then postmultiplying by $\mathbf{A}$, we obtain

$$
\frac{1}{M} \mathbf{P} \frac{\partial \mathbf{q}}{\partial \mathbf{a}^{\prime}} \mathbf{A}=-\frac{1}{M} \mathbf{P} \frac{\partial \mathbf{q}^{*}}{\partial \mathbf{p}^{\prime}} \mathbf{P} \mu \mathrm{A}^{-1} \mathbf{A}=-\frac{1}{M} \mathbf{P} \frac{\partial \mathbf{q}^{*}}{\partial \mathbf{p}^{\prime}} \mathbf{P} \mu
$$

Substituting for $\partial \mathbf{q}^{*} / \partial \mathbf{p}^{\prime}$ from (2.7), the far right-hand side of the above equation becomes

$$
\begin{aligned}
-\frac{1}{M} \mathbf{P} \frac{\partial \mathbf{q}^{*}}{\partial \mathbf{P}^{\prime}} \mathbf{P} \boldsymbol{\mu} & =-\frac{1}{\mathrm{M}} \mathbf{P}\left[\lambda U^{-1}-\frac{\lambda}{\partial \lambda / \partial \mathrm{M}} \frac{\partial \mathbf{q}}{\partial \mathrm{M}} \frac{\partial \mathbf{q}^{\prime}}{\partial \mathrm{M}}\right] \mathbf{P} \boldsymbol{\mu} \\
& =-\left[\frac{\lambda}{M} \mathbf{P U}^{-1} \mathbf{P}-\frac{\lambda \mathrm{M}}{\partial N / \partial \mathrm{M}} \mathbf{P} \frac{\partial \mathbf{q}}{\partial \mathrm{M}} \frac{\partial \mathbf{q}^{\prime}}{\partial \mathrm{M}} \mathbf{P}^{\prime}\right] \mu \\
& =-\left[v-\phi \theta \theta^{\prime}\right] \mu \\
& =-v\left[\mathrm{I}-\iota \theta^{\prime}\right] \mu,
\end{aligned}
$$

where the second step uses $\mathbf{P}=\mathbf{P}^{\prime}$; the third step uses the definitions $v=(\lambda / M) \mathrm{PU}^{-1} \mathrm{P}, \quad \phi=\frac{\lambda / \mathrm{M}}{\partial N / \partial \mathrm{M}}$ and $\theta=\left[\theta_{i}\right]=\mathrm{P}(\partial \mathrm{q} / \partial \mathrm{M}) ;$ and the last step uses constraint $(6.2)$ in the form $v \iota=\phi \theta$, where $\iota=\left[\begin{array}{lll}1 & \ldots & 1\end{array}\right]^{\prime}$. Combining equations (7.2) and (7.3) yields

$$
\frac{1}{\mathrm{M}} \mathrm{P} \frac{\partial \mathrm{q}}{\partial \mathrm{a}^{\prime}} \mathbf{A}=-v\left[\mathrm{I}-\iota^{\prime}\right] \mu
$$


We write (5.1) for $j=1, \ldots, n$ as

$$
d(\log \tilde{a})=\mu d(\log a)
$$

where $d(\log \tilde{a})=\left[d\left(\log \tilde{a}_{j}\right)\right] ; \mu=\left[\mu_{j k}\right] ;$ and $d(\log a)=\left[d\left(\log a_{k}\right)\right]$. We also write (5.2) in the form

$$
d\left(\log \tilde{A}^{\prime}\right)=\theta^{\prime} d(\log \tilde{a})
$$

Postmultiplying both sides of (7.4) by d(log a) gives

$$
\begin{aligned}
& \frac{1}{M} P \frac{\partial q}{\partial a^{\prime}} \operatorname{Ad}(\log a)=-v\left[I-\iota \theta^{\prime}\right] \mu d(\log a) \\
& =-\left[v d(\log \tilde{a})-v \iota d\left(\log \tilde{A}^{\prime}\right)\right] \\
& =\left[-\sum_{j=1}^{n} v_{i j} d\left[\log \frac{\tilde{a_{j}}}{\tilde{A}^{\prime}}\right]\right] \text {, }
\end{aligned}
$$

where the second step uses (7.5) and (7.6); and the last member of (7.7) represents an $\mathrm{n} \times 1$ vector.

Combining equations (7.1) and (7.7) gives

$$
\sum_{j=1}^{n} \frac{p_{i} a_{j}}{M} \frac{\partial q_{i}}{\partial a_{j}} d\left(\log a_{j}\right)=-\sum_{j=1}^{n} v_{i j} d\left[\log \frac{\tilde{a}_{j}}{\tilde{A}^{j}}\right] \text {, }
$$

which is the result given in equation (6.8).

To derive (6.11) consider the negative of the right-hand side of 
equation (7.8)

$$
\begin{aligned}
\sum_{j=1}^{n} v_{i j} d\left[\log \frac{\tilde{a}_{j}}{\tilde{A^{\prime}}}\right] & =\sum_{j=1}^{n} v_{i j} d\left(\log \tilde{a}_{j}\right)-\sum_{j=1}^{n} v_{i j} d\left(\log \tilde{A}^{\prime}\right) \\
& =\sum_{j=1}^{n} v_{i j} d\left(\log \tilde{a}_{j}\right)-\phi \theta_{i} d\left(\log \tilde{A}^{\prime}\right) .
\end{aligned}
$$

where the second step is based on (6.2). Using (6.3) to substitute $\pi_{i j}+\phi \theta_{i}{ }_{j}$ for $v_{i j}$ in the above equation, we obtain

$$
\begin{aligned}
& \sum_{j=1}^{n} v_{i j} d\left(\log \tilde{a}_{j}\right)-\phi \theta_{i} d\left(\log \tilde{A}^{\prime}\right)=\sum_{j=1}^{n}\left(\pi_{i j}+\phi \theta_{i} \theta_{j}\right) d\left(\log \tilde{a}_{j}\right)-\phi \theta_{i} d\left(\log \tilde{A}^{\prime}\right) \\
& =\sum_{j=1}^{n} \pi_{i j} d\left(\log \tilde{a}_{j}\right)+\phi \theta \theta_{j=1}^{n} \theta_{j} d\left(\log \tilde{a}_{j}\right) \\
& -\phi \theta_{i} d\left(\log \tilde{A}^{\prime}\right) \\
& =\sum_{j=1}^{n} \pi_{i j} d\left(\log \tilde{a}_{j}\right) \text {, }
\end{aligned}
$$

where the last step uses (5.2). Combining (7.9) and (7.10) gives

$$
\sum_{j=1}^{n} v_{i j} d\left[\log \frac{\tilde{a_{j}}}{\tilde{A}}\right]=\sum_{j=1}^{n} \pi_{i j} d\left(\log \tilde{a}_{j}\right)
$$

Using (5.1) we write (7.11) as

$$
\sum_{j=1}^{n} v_{i j} d\left[\log \frac{\tilde{a}_{j}}{\tilde{A^{\prime}}}\right]=\sum_{j=1}^{n} \pi_{i j}\left[\sum_{k=1}^{n} \mu_{j k} d\left(\log a_{k}\right)\right]
$$




$$
\begin{aligned}
& =w_{i} \underset{k=1}{n}\left[\sum_{j=1}^{n} \eta_{i j}^{*}{ }_{j k}\right] d\left(\log a_{k}\right) \\
& =-w_{i} \sum_{k=1}^{n} \tau_{i k} d\left(\log a_{k}\right),
\end{aligned}
$$

where the second step uses $\pi_{i j}=w_{i} \eta_{i j}^{*}$ and the last step uses (3.7). Equation (7.12) is equivalent to (6.11).

Finally, we derive equation (6.13). Multiplying both sides of the scalar form of equation (3.7) by $w_{i}$ and substituting $\lambda_{i j}=w_{i}{ }^{T} i j$ and $\pi_{i j}=w_{i} \eta_{i j}^{*}$, we obtain

$$
\lambda_{i j}=-\sum_{k=1}^{n} \pi_{i k} k_{k j} .
$$

If we sum both sides of the above equation over $j=1, \ldots, n$ we obtain

$$
\begin{aligned}
\sum_{j=1}^{n} \lambda_{i j} & =-\sum_{j=1}^{n}\left[\sum_{k=1}^{n} \pi_{i k} \mu_{k j}\right] \\
& =-\sum_{k=1}^{n}\left[\sum_{j=1}^{n} \mu_{k j}\right] \pi_{i k} \\
& =-\mu_{0} \underset{k=1}{n} \pi_{i k} \\
& =0,
\end{aligned}
$$

where the third step uses (5.6) and the last step uses (6.4). This is equation (6.13). 


\section{Block Independence}

In this section initially we review the material on block independence from Theil (1980a). We then discuss extensions for advertising.

\section{Previous Results}

We partition the $\mathrm{n}$ goods into $\mathrm{G}$ groups, $\mathrm{s}_{1}, \ldots, \mathrm{s}_{\mathrm{G}}$. The $\mathrm{g}^{\text {th }}$ group consists of $\mathrm{n}_{\mathrm{g}}$ goods so that $\sum_{\mathrm{g}=1}^{\mathrm{G}} \mathrm{n}_{\mathrm{g}}=\mathrm{n}$. Under block independence the consumer's utility function (2.1) becomes

$$
u(q)=\sum_{g=1}^{G} u_{g}\left(q_{g}\right) \text {, }
$$

where $q_{g}$ is the vector of $q_{i}$ 's that fall under $s_{g}$. Specification (8.1) implies that price coefficient matrix is block diagonal.

$$
v=\operatorname{diag}\left[v_{1} \ldots v_{\mathrm{G}}\right]
$$

In other words, $v_{i j}=0$ for $i \in S_{g}$ and $j \notin S_{g}$.

In view of (8.2), under block independence the demand equation (6.1) for $i \in S_{g}$ becomes

$$
w_{i} d\left(\log q_{i}\right)=\theta_{i} d(\log Q)+\sum_{j \in S_{g}} v_{i j} d\left[\log \frac{p_{j}}{P^{\prime}}\right] .
$$




\section{An Extension}

Under block independence the consumer's utility function (2.10) becomes

$$
u(q, a)=\sum_{g=1}^{G} u_{g}\left(q_{g}, a_{g}\right),
$$

where $\mathrm{a}_{\mathrm{g}}$ is the sub-vector of a containing the goods that fall under $\mathrm{S}_{\mathrm{g}}$. This formulation of the utility function is the natural extension of (8.1). As before with specification (8.1), (8.4) implies that the price coefficient matrix is block diagonal as indicated by (8.2).

Under (8.4) we have

$$
\frac{\partial^{2} u}{\partial q_{i} \partial a_{j}}=0
$$

for every $i \in S_{g}, j \in S_{h}, g \neq h$.

In words, (8.5) states that the marginal utility of a good which belongs to group $\mathrm{S}_{\mathrm{g}}$ does not depend on the advertising of a good belonging to some other group. From (8.5) it is clear that the Hessian of the utility function (8.4) is block diagonal. Using equation (3.4), equation (8.5) implies

$$
\mu_{i j}=0,
$$$$
i \in S_{g}, j \in S_{h}, g \neq h \text {. }
$$

We return to restriction (5.6) and write it in the form

$$
\sum_{j=1}^{n} \mu_{i j}=\mu_{0} \text {, }
$$


In view of (8.6), for $i \in S_{g}$ this becomes

$$
\sum_{j \in S_{g}} \mu_{i j}=\mu_{0}
$$

Equation (8.7) says that for any given $i \in S_{g}$, the sum of the advertising elasticities over $\mathrm{j} \in \mathrm{S}_{\mathrm{g}}$ is a constant $\mu_{\mathrm{o}}$. This constant is interpreted as the percentage increase in the marginal utility of $i$ resulting from a one percent increase in advertising of each of the goods belonging to the same group as $i$.

Under block independence the demand equation (6.9) for $i \in \mathrm{S}_{\mathrm{g}}$ becomes

$$
w_{i} d\left(\log q_{i}\right)=\theta_{i} d(\log Q)+\sum_{j \in S_{g}} v_{i j}\left[d\left[\log \frac{p_{j}}{P^{\prime}}\right]-d\left[\log \frac{\tilde{a}_{j}}{\tilde{A}^{\prime}}\right]\right] .
$$

Under restrictions (8.6) and (8.7), an equiproportionate change in all advertising variables in $S_{g}$ implies that $d\left(\log \tilde{a}_{j}\right)=\mu_{o} d(\log a)$; this follows from (5.1). Equation (5.3) implies that $d\left(\log \tilde{A}^{\prime}\right)=\mu_{0} d(\log a)$. Hence the relative advertising term in (8.8), $d\left(\log \tilde{a}_{j} / \tilde{A}^{\prime}\right)$, will be zего.

Below equation (5.6) we pointed out that $d\left(\log \tilde{a}_{j}\right)=d\left(\log a_{j}\right)$ and $d\left(\log \tilde{A}^{\prime}\right)=d\left(\log A^{\prime}\right)$ when $\mu_{i j}=\delta_{i j}$. In this case the last term of equation (8.8) becomes

$$
\sum_{j \in S_{g}} v_{i j}\left[d\left[\log \frac{p_{j}}{P^{\prime}}\right]-d\left[\log \frac{a_{j}}{A^{\prime}}\right]\right]
$$


Below equation (5.7) we showed that $\mu_{i j}=\mu \delta_{i j}$ implies $d\left(\log \tilde{a}_{i}\right)=\mu d\left(\log a_{i}\right)$ and $d\left(\log \tilde{A}^{\prime}\right)=\mu d\left(\log A^{\prime}\right)$. Thus the last term of equation (8.8) simplifies to

$$
\underset{j \in S_{g}}{\sum} v_{i j}\left[d\left[\log \frac{p_{j}}{P^{\prime}}\right]-\mu d\left[\log \frac{a_{j}}{A^{\prime}}\right]\right]
$$

As can be seen from equations (8.9) and (8.10), under these two special cases, the demand equation for good $i \in S_{g}$, equation (8.8), contains only the advertising of goods which belong to the same group as does $i$.

\section{A Groupwise Index of Advertising}

In Section 5 we introduced indexes of advertising of all $\mathrm{n}$ goods. In this section we develop an index of advertising for a group of commodities. This group index will be used in the composite and conditional demand equations which are derived in subsequent sections.

Consider a conditional-marginal-share-weighted average of $\left\{d\left(\log \tilde{a}_{k}\right), k \in s_{g}\right\}$,

$$
d\left(\log \tilde{A}_{g}^{\prime}\right)=\sum_{k \in S_{g}} \theta_{j^{\prime}} d\left(\log \tilde{a}_{k}\right),
$$

where $\theta_{\mathrm{k}}=\theta_{\mathrm{k}} / \theta_{\mathrm{g}}$ is the conditional marginal share of $i$; and $\theta_{\mathrm{g}}$ is the group marginal share. The above advertising index aggregates consistently since a group-marginal-share-weighted average of $d\left(\log \tilde{A}_{1}^{\prime}\right), \ldots, d\left(\log \tilde{A}_{G}^{\prime}\right)$ equals the overall advertising index $d\left(\log \tilde{A}^{\prime}\right)$ 
defined by $(5.2)$ :

$\sum_{g=1}^{G} \theta_{g} d\left(\log \tilde{A}_{g}^{\prime}\right)=\sum_{g=1}^{G} \theta_{g} \underset{k \in S_{g}}{\sum} \theta_{k}^{\prime} d\left(\log \tilde{a}_{k}\right)=\sum_{k=1}^{n} \theta_{k} d\left(\log \tilde{a}_{k}\right)=d\left(\log \tilde{A}^{\prime}\right)$.

Substituting for $d\left(\log \tilde{a}_{k}\right)$ from $(5.1)$ in (9.1) and using (8.6) we can express the group advertising index in terms of $\left\{d\left(\log a_{j}\right), j \in s_{g}\right\}$ :

$$
\begin{aligned}
\mathrm{d}\left(\log \tilde{A}_{\mathrm{g}}^{\prime}\right)=\sum_{j \in S_{g}} \theta_{j}^{\prime} \mathrm{d}\left(\log \tilde{a}_{j}\right) & =\sum_{j \in S_{g}} \theta_{j}^{\prime} \sum_{k=1}^{n} \mu_{j k} d\left(\log a_{k}\right) \\
& =\sum_{j \in S_{g}} \theta_{j}^{\prime} \sum_{k \in S_{g}}^{\sum} \mu_{j k} d\left(\log a_{k}\right) \\
& =\sum_{k \in S_{g}} h_{k}^{\prime} d\left(\log a_{k}\right),
\end{aligned}
$$

where

$$
h_{k}^{\prime}=\sum_{j \in S_{g}} \theta_{j}^{\prime} \mu_{j k}
$$

Under constraint (8.6) the weights used in equation (5.3), $h_{k}$ for $\mathrm{k} \in \mathrm{S}_{\mathrm{g}}$, become

$$
h_{k}=\underset{j \in S_{g}}{\theta_{j}{ }_{j k}}=\theta_{g} h_{k}^{\prime}
$$

where we have used (9.3) and $\theta_{j}=\theta_{g^{\prime}} \theta_{j}^{\prime}$. Equation (9.2) shows that the weighted average given by (9.1) can be considered as an index of the advertising of the goods in $\mathrm{S}_{\mathrm{g}}$ only. If we sum both sides of (9.3) over 
$k \in S_{g}$ we get

$$
\underset{\mathrm{k} \in S_{\mathrm{g}}}{\Sigma} h_{\mathrm{k}}^{\prime}=\sum_{\mathrm{k} \in S_{\mathrm{g}}} \sum_{j \in S_{g}} \theta_{j}^{\prime} \mu_{j k}=\sum_{j \in S_{g}} \theta_{j}^{\prime}\left[\sum_{k \in S_{g}} \mu_{j k}\right]=\mu_{0},
$$

where the last step uses $\Sigma_{j \in S_{g}}^{\theta_{j}^{\prime}}=1$ and equation (8.7). Furthermore, this result implies that

$$
\underset{\mathrm{k} \in \mathrm{S}_{\mathrm{g}}}{\Sigma} \mathrm{h}_{\mathrm{k}}=\theta_{\mathrm{g}} \underset{\mathrm{k} \in \mathrm{S}_{\mathrm{g}}}{\Sigma} \mathrm{h}_{\mathrm{k}}^{\prime}=\theta_{\mathrm{g}}^{\mu}{ }_{\mathrm{o}}
$$

When $\mu_{j k}=\delta_{j k}, d\left(\log \tilde{A}_{g}^{\prime}\right)$ becomes a conditional marginal-shareweighted average of $\left\{d\left(\log a_{i}\right), i \in S_{g}\right\}$ which we write as

$$
d\left(\log A_{g}^{\prime}\right)=\sum_{i \in S_{g}} \theta_{i}^{\prime} d\left(\log a_{i}\right)
$$

This is a Frisch index of advertising for the group $\mathrm{S}_{\mathrm{g}}$. If $\mu_{\mathrm{jk}}=\mu \delta_{j k}$, then the advertising index $d\left(\log \tilde{A}_{g}^{\prime}\right)$ is a multiple of $\mu$ of the Frisch index for the group.

Consider

$$
\mathrm{d}\left[\log \frac{\tilde{A}_{\mathrm{g}}^{\prime}}{\tilde{A}^{\prime}}\right]=\mathrm{d}\left(\log \tilde{A}_{g}^{\prime}\right)-\mathrm{d}\left(\log \tilde{A}^{\prime}\right)
$$

Equation (9.2) shows that the index $d\left(\log \tilde{A}_{g}^{\prime}\right)$ can be expressed as a weighted sum of the advertising of goods that belong to $\mathrm{S}_{\mathrm{g}}$. Therefore the index $d\left(\log \tilde{A}_{g}^{\prime} \tilde{A}^{\prime}\right)$ can be considered as a relative advertising index for the group $S_{g}$. This index is analogous to the index of the relative price of $S_{g}, d\left(\operatorname{Iog} P_{g}^{\prime} / P^{\prime}\right)$. 
Consider the situation when there is an equiproportionate change in the advertising of each good, so that $d\left(\log a_{i}\right)=d(\log a)$ for all $i$. Then from (5.1) we have $d\left(\log \tilde{a}_{j}\right)=\sum_{k=1}^{n} \mu_{j k} d\left(\log a_{k}\right)=\mu_{o} d(\log a)$. Substituting this result in (5.2) and (9.1) we get $d\left(\log \tilde{A}^{\prime}\right)=\mu_{0} d(\log a)$ and $d\left(\log \tilde{A}_{g}^{\prime}\right)=\mu_{0} d(\log a)$. Hence the advertising index defined in $(9.6)$ becomes $d\left(\log \tilde{A}_{g}^{\prime} \tilde{A}^{\prime}\right)=d\left(\log \tilde{A}_{g}^{\prime}\right)$ $d\left(\log \tilde{A}^{\prime}\right)=0$. Consequently, the relative advertising index of $\mathrm{S}_{\mathrm{g}}$ vanishes when there is an equiproportionate change in the advertising of all members of $\mathrm{S}_{\mathrm{g}}$.

\section{The Composite Demand Equation}

In this section initially we give a brief summary of the results on composite demand equation for the group $\mathrm{S}_{\mathrm{g}}$ from Theil (1980a) and then extend the composite demand equation to deal with advertising.

\section{Previous Results}

Summation of both sides of equation (8.3) over $i \in \mathrm{S}_{\mathrm{g}}$ yields the composite demand equation for $S_{g}$,

$$
W_{g} d\left(\log Q_{g}\right)=\theta_{g} d(\log Q)+\phi \theta_{g} d\left[\log \frac{P^{\prime}}{P^{\prime}}\right]
$$

where $W_{g}=\Sigma_{i \in S_{g}} W_{i}$ is the group budget share; $d\left(\log Q_{g}\right)$ is the Divisia volume index of $\mathrm{S}_{\mathrm{g}} ; \theta_{\mathrm{g}}=\Sigma_{\mathrm{i} \in \mathrm{S}_{\mathrm{g}}} \theta_{i}$ is the marginal share of $\mathrm{S}_{\mathrm{g}}$; $d(\log Q)$ is the change in real income; $\phi$ is the income flexibility; $\mathrm{d}\left(\log \mathrm{P}_{\mathrm{g}}^{\prime}\right)=\Sigma_{i \in \mathrm{S}_{\mathrm{g}}} \theta_{i}^{\prime} \mathrm{d}\left(\log \mathrm{P}_{\mathrm{i}}\right)$ is the Frisch price index of $\mathrm{S}_{\mathrm{g}} ;$ and $d\left(\log P^{\prime}\right)$ is the overall Frisch price index. 


\section{An Extension}

If we add (8.8) over $i \in S_{g}$ we get $W_{g} d\left(\log Q_{g}\right)$ on the left and $\theta_{\mathrm{g}} \mathrm{d}(\log Q)$ as the first term on the right. The term dealing with price substitution and advertising is

$$
\sum_{i \in S_{g}} \sum_{j \in S_{g}} v_{i j}\left[\mathrm{~d}\left[\log \frac{\mathrm{p}_{j}}{\mathrm{P}^{\mathrm{j}}}\right]-\mathrm{d}\left[\log \frac{\tilde{\mathrm{a}}_{\mathrm{j}}}{\tilde{\mathrm{A}}^{\mathrm{j}}}\right]\right] \text {. }
$$

The double summation of the price term can be expressed as

$$
\sum_{i \in S_{g}} \sum_{j \in S_{g}} v_{i j} d\left[\log \frac{p_{j}}{P^{\prime}}\right]=\phi \theta_{g^{d}}\left[\log \frac{P_{g}^{\prime}}{P^{\prime}}\right]
$$

In Section 14 we show that

$$
\sum_{i \in S_{g}} \sum_{j \in S_{g}} v_{i j} \mathrm{~d}\left[\log \frac{\tilde{a}_{j}}{\tilde{A^{\prime}}}\right]=\phi \theta_{g} d\left[\log \frac{\tilde{A}_{g}^{\prime}}{\tilde{A}^{\prime}}\right]
$$

which is analogous to $(10.3)$.

Using (10.3) and (10.4), the composite demand equation for $\mathrm{S}_{\mathrm{g}}$ is thus

$$
W_{\mathrm{g}} \mathrm{d}\left(\log \mathrm{Q}_{\mathrm{g}}\right)=\theta_{\mathrm{g}^{\mathrm{d}}} \mathrm{d}(\log \mathrm{Q})+\phi \theta_{\mathrm{g}}\left[\mathrm{d}\left[\log \frac{\mathrm{P}_{\mathrm{g}}^{\prime}}{\mathrm{P}^{\prime}}\right]-\mathrm{d}\left[\log \frac{\tilde{\mathrm{A}}_{\mathrm{g}}^{\prime}}{\tilde{\mathrm{A}}^{\prime}}\right]\right] .
$$

Equation (10.5) is the extended composite demand equation for $\mathrm{S}_{\mathrm{g}}$ as a 
group. This equation shows that under block independence, the demand for a group as a whole depends on real income, the relative price of the group, $d\left(\log \mathrm{P}_{\mathrm{g}}^{\prime} / \mathrm{P}^{\prime}\right)$, and the relative advertising of the group, $\mathrm{d}\left(\log \tilde{A}_{\mathrm{g}}^{\prime} / \tilde{A}^{\prime}\right)$. From the discussion given below equation (9.6) it is clear that the relative advertising index of the group $d\left(\log \tilde{A}_{g}^{\prime} / \tilde{A}^{\prime}\right)$ depends only on those goods that belong to $\mathrm{S}_{\mathrm{g}}$. Thus the relative prices and relative advertising of goods outside the group do not play any role in the extended composite demand equation. As stated below equation (9.6), an equiproportionate change in the advertising of all goods means that the relative advertising term becomes zero. Dividing both sides of equation (10.5) by $W_{g}$ we find that the elasticity of the demand for $S_{g}$ as a whole with respect to its relative advertising is $-\phi \theta_{\mathrm{g}} / \mathrm{W}$, which is the same in absolute value as the elasticity with respect to the relative price. This result implies that under block independence, groups of goods which are more price sensitive (i.e., those which have more substitutes) are more responsive to advertising.

Under the special case (4.1), $d\left(\log \tilde{a}_{j}\right)=d\left(\log a_{j}\right)$, $d\left(\log \tilde{A}^{\prime}\right)=d\left(\log A^{\prime}\right)$ and $d\left(\log \tilde{A}_{g}^{\prime}\right)=d\left(\log A_{g}^{\prime}\right)$. Hence the last term of the composite demand equation (10.5) becomes

$$
\phi \theta_{g}\left[\mathrm{~d}\left[\log \frac{\mathrm{P}^{\prime}}{\mathrm{P}^{\prime}}\right]-\mathrm{d}\left[\log \frac{\mathrm{A}_{\mathrm{g}}^{\prime}}{\mathrm{A}^{\prime}}\right]\right]
$$

For the other special case, $\mu=\mu I, d\left(\log \tilde{a}_{j}\right)=\mu d\left(\log a_{j}\right)$, $\mathrm{d}\left(\log \tilde{\mathrm{A}}^{\prime}\right)=\mu \mathrm{d}\left(\log \mathrm{A}^{\prime}\right)$ and $\mathrm{d}\left(\log \tilde{A}_{\mathrm{g}}^{\prime}\right)=\mu \mathrm{d}\left(\log \mathrm{A}_{\mathrm{g}}^{\prime}\right)$. Therefore the last term of (10.5) simplifies to

$$
\phi \theta_{\mathrm{g}}\left[\mathrm{d}\left[\log \frac{\mathrm{P}^{\prime}}{\mathrm{P}^{\prime}}\right]-\mu \mathrm{d}\left[\log \frac{\mathrm{A}_{\mathrm{g}}^{\prime}}{\mathrm{A}^{\prime}}\right]\right]
$$




\section{Conditional Demand Equations}

In this section we first give a brief review of the results on conditional demand equations from Theil (1980a). We then analyse the extension for advertising.

\section{Previous Results}

By combining equations (8.3) and (10.1) to eliminate $d(\log Q)$ and $d\left(\log P^{\prime}\right)$ we obtain the conditional demand equations for $i \in S_{g}$,

$$
w_{i} d\left(\log q_{i}\right)=\theta_{i} W_{g} d\left(\log Q_{g}\right)+\sum_{j \in S_{g}} v_{i j} d\left[\log \frac{p_{j}}{P_{g}^{\prime}}\right]
$$

This shows that only variables pertaining to the group $S_{g}$ to which $i$ belongs affect the demand for that good.

\section{An Extension}

To obtain the advertising extension of (11.1), we combine equations (8.8) and (10.5) to give

$$
W_{i} d\left(\log q_{i}\right)=\theta_{i}^{\prime} W_{g} d\left(\log Q_{g}\right)+\sum_{j \in S_{g}} v_{i j}\left[d\left[\log \frac{P_{j}}{P_{g}^{\prime}}\right]-d\left[\log \frac{\tilde{a}_{j}}{\tilde{A}_{g}^{\prime}}\right]\right]
$$

This is the extended version of the conditional demand equation for $i$ in terms of relative prices and advertising.

When $\mu_{i j}=\delta_{i j}$, we have $d\left(\log \tilde{a}_{j}\right)=d\left(\log a_{j}\right)$ and $d\left(\log \tilde{A}_{g}^{\prime}\right)=d\left(\log A_{g}^{\prime}\right)$. Consequently the last term of the above equation 
becomes

$$
\underset{j \in S_{g}}{\sum} v_{i j}\left[d\left[\log \frac{p_{j}}{P_{g}^{\prime}}\right]-d\left[\log \frac{a_{j}}{A_{g}^{\prime}}\right]\right] .
$$

For the case $\mu_{i j}=\mu \delta_{i j}$, this last term simplifies to

$$
\underset{j \in S_{g}}{\sum} v_{i j}\left[d\left[\log \frac{p_{j}}{P_{g}^{\prime}}\right]-\mu d\left[\log \frac{a_{j}}{A_{g}^{\prime}}\right]\right]
$$

\section{Conditional Demand Equations in Absolute Prices}

In the last section we derived the extended version of the conditional demand equations in relative prices and advertising. In this section we formulate these demand equations in terms of absolute prices and advertising. As before, we commence with a brief restatement of the previous results from Theil (1980a).

\section{$\underline{\text { Previous Results }}$}

We define the conditional Slutsky coefficients as

$$
\prod_{i j}^{g}=v_{i j}-\phi \theta_{g} \theta_{i}^{\prime} \theta_{j}^{\prime}
$$

These Slutsky coefficients satisfy symmetry

$$
\mathbb{\pi}_{i j}^{g}=\pi_{j i}^{g},
$$


and homogeneity

$$
\sum_{j \in S} \pi_{i j}^{g}=0
$$

Equations (12.1) and (12.2) are the conditional versions of equations (6.3) and (6.4).

Substituting for $v_{i j}$ from (12.1) we can write the price substitution term in (11.1) as

$$
\sum_{j \in S_{g}} v_{i j} d\left[\log \frac{p_{j}}{P_{g}^{\prime}}\right]=\sum_{j \in S_{g}} \frac{g}{i j} d\left(\log p_{j}\right)
$$

This is the conditional version of (6.5). In view of (12.3), the conditional demand equation (11.1) can be written as

$$
w_{i} d\left(\log q_{i}\right)=\theta_{i}^{\prime} W_{g} d\left(\log Q_{g}\right)+\underset{j \in S_{g}}{\pi_{i j}^{g}} d\left(\log p_{j}\right)
$$

This is the conditional demand equation for $i \in S_{g}$ in terms of absolute prices.

\section{An Extension}

We define

$$
\lambda_{i j}^{g}=-\sum_{k \in S} \pi_{i k}^{g} \mu_{k j}
$$

In Section 14 we show that the negative of the advertising term of 
equation (11.2) is

$$
\sum_{j \in S_{g}} v_{i j} d\left[\log \frac{\tilde{a}_{j}}{\tilde{A_{g}^{\prime}}}\right]=-\sum_{j \in S_{g}} \lambda_{i j}^{g} d\left(\log a_{j}\right)
$$

Using the above result and (12.3) we can write equation (11.2) as

$$
w_{i} d\left(\log q_{i}\right)=\theta_{i}^{\prime} W_{g} d\left(\log Q_{g}\right)+\sum_{j \in S_{g}} \pi_{i j}^{g} d\left(\log p_{j}\right)+\sum_{j \in S} \lambda_{i j}^{g} d\left(\log a_{j}\right) .
$$

This is the extended version of the conditional demand equation for commodity $i$ in terms of absolute prices and advertising. The coefficient $\lambda_{i j}^{g}$ measures the effect of a change in the advertising of good $j$ on the consưmption of good $i\left(i, j \in S_{g}\right)$ under the conditions that prices, the advertising of goods other than $j$ and total consumption of the group remain constant.

Obviously, in general, $\lambda_{i j}^{g} \neq \lambda_{j i}^{g}$. Summing both sides of (12.5) over $j \in S_{g}$ and using (8.7) and (12.2) we obtain, for $i \in S_{g}$,

$$
\begin{aligned}
\sum_{j \in S_{g}} \lambda_{i j}^{g} & =-\sum_{k \in S}\left[\sum_{j \in S_{g}} \mu_{k j}\right] \pi_{i k}^{g} \\
& =-\mu_{0} \underset{k \in S_{g}}{\pi_{i k}^{g}} \\
(12.8) & =0 .
\end{aligned}
$$

Using (12.7) we can interpret (12.8) as stating that an equiproportionate change in all the advertising variables $a_{j}, j \in S_{g}$, 
has no effect on consumption of good $i \in S_{g}$ under the condition that total consumption of the group and prices of all goods belonging to $\mathrm{S}_{\mathrm{g}}$ remain constant.

$$
\begin{gathered}
\text { When } \mu_{i j}=\delta_{i j} \text {, equation (12.5) implies that } \\
\lambda_{i j}^{g}=-\pi_{i j}^{g} .
\end{gathered}
$$

Consequently, the last two terms of (12.7) become

$$
\sum_{j \in S_{g}} \prod_{i j}^{g}\left[d\left(\log p_{j}\right)-d\left(\log a_{j}\right)\right]
$$

It also follows from (12.5) that when $\mu_{i j}=\mu \delta_{i j}, \lambda_{i j}^{g}=-\mu \pi_{i j}^{g}$. In this case the last two terms of (12.7) simplify to

$$
\underset{j \in S}{\sum} \pi_{i j}^{g}\left[d\left(\log p_{j}\right)-\mu d\left(\log a_{j}\right)\right]
$$

It should also be noted that both special cases imply that $\lambda_{i j}^{g}=\lambda_{j i}^{g}$ for i, $j \in S_{g}$.

\section{The Unconditional Demand Equations}

In Section 6 we derived the unconditional demand equations. In Sections 10-12 we derived the composite and conditional demand equations under block independence. In this section we develop the relationship between the conditional price and advertising coefficients, on the one hand, and their unconditional counterparts, on the other.

We re-write the relative price and advertising terms of the 
composite demand equation (10.5) in the form

$$
\mathrm{d}\left[\log \frac{\mathrm{P}^{\prime}}{\mathrm{P}^{\prime}}\right]=\sum_{j \in S_{g}} \theta_{j}^{\prime} \mathrm{d}\left(\log \mathrm{p}_{j}\right)-\mathrm{d}\left(\log P^{\prime}\right)
$$

and

$$
\mathrm{d}\left[\log \frac{\tilde{A_{g}^{\prime}}}{\tilde{A^{\prime}}}\right]=\sum_{j \in S} h_{j}^{\prime} d\left(\log a_{j}\right)-d\left(\log \tilde{A}^{\prime}\right)
$$

where we have used equation (9.2). Thus equation (10.5) can be expressed as

$$
\begin{aligned}
W_{g} d\left(\log Q_{g}\right)=\theta_{g} d(\log Q) & +\phi \theta_{g}\left[\sum_{j \in S_{g}} \theta_{j}^{\prime} d\left(\log p_{j}\right)-d\left(\log P^{\prime}\right)\right] \\
& -\phi \theta_{g}\left[\sum_{j \in S_{g}} h_{j}^{\prime} d\left(\log a_{j}\right)-d\left(\log \tilde{A}^{\prime}\right)\right] .
\end{aligned}
$$

According to the conditional demand equation (12.7), consumption of good $i$ depends on the total consumption of the group and the prices and advertising of the goods in the group. Equation (13.3) shows the dependence of total consumption of the group on the price of good $j$ and $i$ ts advertising. Thus a change in $p_{j}$ or $a_{j}$ has a direct effect on $i$, via the conditional demand equation, and an indirect effect via the composite demand equation. These two effects can be combined to give the total effect by substituting the right-hand side of (13.3) for $W_{\mathrm{g}} \mathrm{d}\left(\log \mathrm{Q}_{\mathrm{g}}\right)$ in the conditional demand equation (12.7). 
In Section 14 we show that the above substitution yields

$$
\begin{aligned}
w_{i} d\left(\log q_{i}\right)=\theta_{i} d(\log Q) & +\sum_{j \in S_{g}} \pi_{i j} d\left(\log p_{j}\right)+\pi_{i o} d\left(\log P_{0}\right) \\
& +\sum_{j \in S_{g}} \lambda_{i j} d\left(\log a_{j}\right)+\lambda_{i o} d\left(\log A_{0}\right)
\end{aligned}
$$

where $\theta_{i}=\theta_{g} \theta_{i}^{\prime}$ is the unconditional marginal share of $i$;

$$
\pi_{i j}=\pi_{i j}^{g}+\phi \theta_{g}\left(1-\theta_{g}\right) \theta_{i}^{\prime} \theta_{j}^{\prime} \text { and } \pi_{i o}=-\phi \theta_{g}\left(1-\theta_{g}\right) \theta_{i}^{\prime}
$$

are the unconditional Slutsky coefficients;

$$
\lambda_{i j}=\lambda_{i j}^{g}-\phi \theta_{g}\left(1-\theta_{g}\right) \theta_{i}^{\prime} h_{j}^{\prime} \text { and } \lambda_{i o}=\mu_{o} \phi \theta_{g}\left(1-\theta_{g}\right) \theta_{i}^{\prime}
$$

are the unconditional advertising coefficients;

$$
\mathrm{d}\left(\log \mathrm{P}_{\mathrm{o}}\right)=\sum_{i \notin \mathrm{S}_{\mathrm{g}}} \frac{\theta_{i}}{1-\theta_{\mathrm{g}}} \mathrm{d}\left(\log \mathrm{p}_{\mathrm{i}}\right)
$$

is the Frisch price index of goods outside of $\mathrm{S}_{\mathrm{g}}$; and

$$
d\left(\log A_{o}\right)=\sum_{j \notin S} \frac{h_{j}}{\mu_{o}\left(1-\theta_{g}\right)} d\left(\log a_{j}\right)
$$

is an analogous index of advertising.

The unconditional Slutsky coefficients given by (13.5) satisfy 
symmetry and homogeneity,

$$
\pi_{i j}=\pi_{j i}
$$

$$
\sum_{j \in S_{g}} \pi_{i j}+\pi_{i o}=0,
$$

On the other hand, the advertising coefficients given by (13.6) are asymmetric. However, in the special cases when $\mu_{\mathrm{kj}}=\mu \delta_{\mathrm{kj}}$ and $\mu_{k j}=\delta_{k j}, \lambda_{i j}^{g}=\lambda_{j i}^{g}, \theta_{i}^{\prime} h_{j}^{\prime}=\theta_{j}^{\prime} h_{i}^{\prime}$ and hence $\lambda_{i j}=\lambda_{j i}$. The advertising coefficients always satisfy

$$
\sum_{j \in S_{g}} \lambda_{i j}+\lambda_{i o}=0
$$

In deriving (13.9) we have used (12.8) and (9.4).

\section{More Derivations}

We first derive result (10.4). The negative of the advertising term in equation (10.2) is

$$
\begin{aligned}
\sum_{i \in S_{g}} \sum_{j \in S_{g}} v_{i j} d\left[\log \frac{\tilde{a_{j}}}{\tilde{A^{\prime}}}\right] & =\sum_{j \in S_{g}}\left[\sum_{i \in S_{g}} v_{i j}\right] d\left(\log \tilde{a}_{j}\right)-\sum_{j \in S_{g}}\left[\sum_{i \in S_{g}} v_{i j}\right] d\left(\log \tilde{A}^{\prime}\right) \\
& =\phi \theta_{g} \sum_{j \in S_{g}} \theta_{j}^{\prime} d\left(\log \tilde{a}_{j}\right)-\phi \theta_{g} d\left(\log \tilde{A}^{\prime}\right)
\end{aligned}
$$




$$
\begin{aligned}
& =\phi \theta_{\mathrm{g}} \mathrm{d}\left(\log \tilde{\mathrm{A}}_{\mathrm{g}}^{\prime}\right)-\phi \theta_{\mathrm{g}} \mathrm{d}\left(\log \tilde{\mathrm{A}}^{\prime}\right) \\
& =\phi \theta_{\mathrm{g}} \mathrm{d}\left[\log \frac{\tilde{A}_{\mathrm{g}}^{\prime}}{\tilde{A}^{\prime}}\right],
\end{aligned}
$$

where the second step uses (6.2) and (8.2); and the third step uses (9.1). Equation (14.1) is equivalent to (10.4)

To derive (12.6) we substitute for $\pi_{i j}^{g}$ from (12.1) in (12.5) to give

$$
\begin{aligned}
\lambda_{i j}^{g} & =-\sum_{k \in S_{g}}\left(v_{i k}-\phi \theta_{g} \theta_{i}^{\prime} \theta_{k}^{\prime}\right) \mu_{k j} \\
& =-\sum_{k \in S_{g}} v_{i k} \mu_{k j}+\phi \theta_{g} \theta_{i}^{\prime} h_{j}^{\prime}
\end{aligned}
$$

where we have used (9.3). Multiplying both sides of the above equation by $-d\left(\log a_{j}\right)$ and summing over $j \in s_{g}$ we obtain

$$
\begin{aligned}
-\sum_{j \in S_{g}} \lambda_{i j}^{g} d\left(\log a_{j}\right) & =\sum_{k \in S_{g}} v_{i k}\left[\sum_{j=1}^{n} \mu_{k j} d\left(\log a_{j}\right)\right]-\phi \theta_{g} \theta_{i}^{\prime} \sum_{j \in S_{g}} h_{j}^{\prime d}\left(\log a_{j}\right) \\
& =\sum_{k \in S_{g}}^{\sum} v_{i k} d\left(\log \tilde{a}_{k}\right)-\sum_{k \in S_{g}} v_{i k} d\left(\log \tilde{A}_{g}^{\prime}\right) \\
& =\sum_{j \in S_{g}} v_{i j} d\left[\log \frac{\tilde{a}_{j}}{\tilde{A}_{g}^{\prime}}\right]
\end{aligned}
$$

where the first step uses (8.6); and the second step uses (5.1), (9.2) and $\Sigma_{j \in S_{g}} v_{i j}=\phi \theta_{g} \theta_{i}^{\prime}$. This is equation (12.6). 
Finally, we derive (13.4). Substituting the right-hand side of (13.3) for $W_{g} d\left(\log Q_{g}\right)$ in equation (12.7) we obtain

$$
\begin{aligned}
w_{i} d\left(\log q_{i}\right) & =\theta_{i}^{\prime}\left[\theta_{g} d(\log Q)+\phi \theta_{g}\left[\sum_{j \in S_{g}} \theta_{j}^{\prime} d\left(\log p_{j}\right)-d\left(\log P^{\prime}\right)\right]\right. \\
& \left.-\phi \theta_{g}\left[\sum_{j \in S} h_{j}^{\prime} d\left(\log a_{j}\right)-d\left(\log \tilde{A}^{\prime}\right)\right]\right]+\sum_{j \in S_{g}} \pi_{i j}^{g} d\left(\log p_{j}\right) \\
& +\underset{j \in S_{g}}{ } \lambda_{i j}^{g} d\left(\log a_{j}\right) .
\end{aligned}
$$

We write the overall Frisch price index $d\left(\log P^{\prime}\right)$ as

$$
\begin{aligned}
& d\left(\log P^{\prime}\right)=\sum_{j=1}^{n} \theta_{j} d\left(\log p_{j}\right)
\end{aligned}
$$

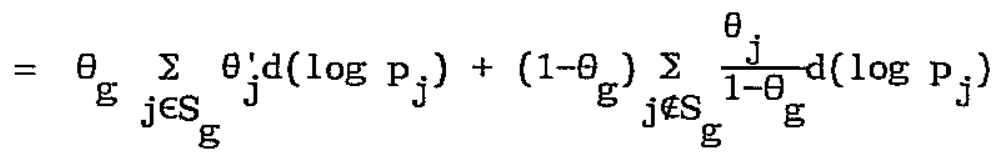

$$
\begin{aligned}
& =\theta_{g} \sum_{j \in S_{g}} \theta_{j}^{\prime} d\left(\log p_{j}\right)+\left(1-\theta_{g}\right) d\left(\log P_{o}\right) .
\end{aligned}
$$

where $d\left(\log P_{0}\right)=\Sigma_{j \notin S}\left[\theta_{j} /\left(1-\theta_{g}\right)\right] d\left(\log P_{j}\right)$ is the Frisch price index of the goods not in $\mathrm{S}_{\mathrm{g}}$.

Similarly, we write the overall advertising index $d\left(\log \tilde{A}^{\prime}\right)$ as

$$
\begin{aligned}
\mathrm{d}\left(\log \tilde{A}^{\prime}\right) & =\sum_{j=1}^{n} h_{j} d\left(\log a_{j}\right) \\
& =\theta_{g} \sum_{j \in S_{g}} h_{j}^{\prime} d\left(\log a_{j}\right)+\mu_{o}\left(1-\theta_{g}\right) \sum_{j \notin S_{g}} \frac{h_{j}}{\mu_{o}\left(1-\theta_{g}\right)} d\left(\log a_{j}\right)
\end{aligned}
$$


$(14.4)$

$$
=\theta_{g} \sum_{j \in S_{g}} h_{j}^{\prime} d\left(\log a_{j}\right)+\mu_{o}\left(1-\theta_{g}\right) d\left(\log A_{o}\right),
$$

where $d\left(\log A_{o}\right)=\Sigma_{j \notin S}\left[h_{j} / \mu_{o}\left(1-\theta_{g}\right)\right] d\left(\log a_{j}\right)$ and $h_{k}=\theta_{g} h_{k}^{\prime}$.

Substituting the right-hand sides of equations (14.3) and (14.4) for $d\left(\log P^{\prime}\right)$ and $d\left(\log \tilde{A}^{\prime}\right)$ in $(14.2)$ and rearrangement of that equation gives

$$
\begin{aligned}
w_{i} d\left(\log q_{i}\right)=\theta_{i} d(\log Q) & +\sum_{j \in S_{g}} \pi_{i j} d\left(\log P_{j}\right)+\pi_{i o} d\left(\log P_{o}\right) \\
& +\sum_{j \in S_{g}} \lambda_{i j} d\left(\log a_{j}\right)+\lambda_{i o} d\left(\log A_{o}\right) .
\end{aligned}
$$

where $\theta_{i}=\theta_{g} \theta_{i}^{\prime} ; \quad \pi_{i j}=\pi_{i j}^{g}+\phi \theta_{g}\left(1-\theta_{g}\right) \theta_{i}^{\prime} \theta_{j}^{\prime}, \quad \pi_{i o}=-\phi \theta_{g}\left(1-\theta_{g}\right) \theta_{i}^{\prime} ;$ $\lambda_{i j}=\lambda_{i j}^{g}-\phi \theta_{g}\left(1-\theta_{g}\right) \theta_{i}^{\prime} h_{j}^{\prime}, \lambda_{i o}=\phi \theta_{g}\left(1-\theta_{g}\right) \mu_{0} \theta_{i}^{\prime}$. This is equation (13.4). 


\section{REFERENCES}

Barten, A.P. (1964). 'Consumer Demand Functions Under Conditions of Almost Additive Preferences,' Econometrica 32 : 1-38.

(1977). 'The Systems of Consumer Demand Functions Approach: A Review,' Econometrica 45: 23-51.

Selvanathan, E. A. (1987). 'The Effects of Advertising on Alcool. Consumption: An Empirical Analysis.' Forthcoming Discussion Paper, Department of Economics, The University of Western Australia.

Theil, H. (1980a). The System-Wide Approach to Microeconomics. University of Chicago Press.

(1980b). System-Wide Explorations in International Economics, Input-Output Analysis, and Marketing Research. Amsterdam: North-Holland Publishing Company. 